\title{
The combination of Taguchi and Proximity Indexed Value methods for multi-criteria decision making when milling
}

\author{
Nguyen Lam Khanh, Nguyen Van Cuong* \\ University of Transport and Communications, Hanoi, Vietnam \\ *Email: nguyencuong@utc.edu.vn
}

Received: February 27, 2021. Revised: July 29, 2021. Accepted: August 25, 2021. Published: August 27, 2021.

\begin{abstract}
Milling is a commonly used method in mechanical machining. This is considered to be the method for the highest productivity among cutting methods. Moreover, the quality of the machined surface is increasingly improved as well as the machining productivity is increasingly enhanced thanks to the development of machine tool and cutting tool manufacturing technology. Therefore, in each specific processing condition (about machine, tool and part material, and other conditions), specific studies are required to determine the value of technological parameters in order to improve productivity and machining accuracy. Only in this way can we take full advantage of the capabilities of modern equipment. The process parameters in the milling method in particular and in the machining and cutting methods in general can be easily adjusted by the machine operator as the parameters of the cutting parameters or the change of tool types. In this article, the combination of Taguchi and Proximity Indexed Value (PIV) methods is presented for multi-criteria decision making in milling. An experimental matrix was designed according to Taguchi method with five input parameters, including the insert materials ( $\mathrm{TiN}, \mathrm{TiCN}$, and $\mathrm{TiAlN}$ ), nose radius, cutting velocity, feed rate and depth of cut. The total number of experiments that were performed was twenty-seven. The workpiece used during the experiment was SCM440 steel. At each experiment, the surface roughness was measured and the Material Removal Rate $(M R R)$ was calculated. The weights of these two parameters have been chosen by the decision maker on the basis of consultation with experts. The $P I V$ method was applied to determine the experiment at which the minimum surface roughness and the maximum $M R R$ were simultaneously guaranteed. In addition, the influence of input parameters on surface roughness was also found in this study.
\end{abstract}

Keywords: Milling, Multi-criteria decision-making, Taguchi, PIV, surface roughness, MRR

\section{INTRODUCTION}

Milling is a very commonly used method in mechanical machining. This is considered to be the most productive of all cutting methods $[1,2]$. On the other hand, with the development of the manufacturing technology of machine tools and cutting tools as well as many other factors, the milling method also provides more and more high accuracy. In order to fully exploit the advantages of equipment and tools in the milling field, a number of studies have been conducted to determine the value of technological parameters for the purpose of simultaneously ensuring certain criteria. This problem is known as multi-criteria decision making in milling (some studies also call this type of multi-criteria decision making problem a multiple objective optimization problem).

There are many mathematical methods for multi-criteria decision making such as Technique for Order Preference by Similarity to Ideal Solution (TOPSIS) [3], VIKOR [4], Multiobjective Optimization On the basis of Ratio Analysis (MOORA) [5] ], COmplex PROportional ASsessment (COPRAS) [6], Reference Ideal Method (RIM) [7], Proximity indexed value (PIV) [8] etc. Several of these methods have been combined with the Taguchi method for multi-criteria decision making during the milling process.

The Taguchi and MOORA methods were combined to make a decision for choosing the value of cutting parameters to simultaneously ensure the minimum flank wear and the maximum MRR [9]. The authors of this study designed a matrix of experiments according to the Taguchi method with a total of twenty-seven experiments. The test material used was medium steel. As a result, they identified one experiment out of a total of twenty-seven experiments performed (i.e. determining the value of cutting speed, feed rate and depth of cut) in which both roughness and Surface and tool wear are minimized.

The Taguchi and MOORA methods have also been combined to make a decision for choosing the insert material, the cutting velocity and the feed rate in order to simultaneously ensure the minimum surface roughness and the maximum $M R R$ [10]. The type of workpiece material used in this study is the Ti-6Al-4V alloy. Two types of insert have been used, $P V D$ coated and $C V D$ coated. A matrix of eighteen experiments was designed according to the Taguchi method. This study identified the best experiment (out of a total of eighteen experiments performed) where the cutting piece 
material was $C V D$, the cutting speed was $150 \mathrm{~m} / \mathrm{min}$, and the feed rate was $0.09 \mathrm{~mm} / \mathrm{min}$.

The Taguchi method has been combined with the RIM method to determine the material of inserts and the value of the cutting velocity, the feed rate and the depth of cut to ensure simultaneous the minimum surface roughness and the maximum MRR [11]. The test material used was SKD11 steel. In this study, a matrix of twenty-seven experiments was also designed according to the Taguchi method with input parameters being the cutting material (including three types: TiN, TiCN and TiAlN), nose radius, cutting speed, feed rate and depth of cut. This study has determined the experiment in which the insert material is TiCN, $0.3 \mathrm{~mm}$ is the value of the tip radius, $125 \mathrm{~m} / \mathrm{min}$ is the value of the cutting velocity, the feed is $500 \mathrm{~mm} / \mathrm{min}$, and 0.45 is the value of the depth of cut. With these values of the input parameters, the maximum $M R R$, the minimum cutting force and the minimum surface roughness are guaranteed.

However, when using methods such as TOPSIS, VIKOR, MOORA, COPRAS, RIM to rank the alternatives, it is very easy to occur the reversal to solutions. That is, if we add or subtract a certain solution, the order of the previously ranked solutions will not be maintained, sometimes even creating an opposite ranking compared to the original ranking [8]. The $P I V$ method is known as a multi-criteria decision making method which enables to minimize the possibility of reversibility to solutions [8]. This method has been successfully applied in multi-criteria decision making when ranking and selecting E-learning sites [12], for the selection of materials for manufacturing some parts of automobiles [13], for the selection of elements for logistics activities of the EU countries [14], for the selection of additives in a production process [15], etc. However, until now, there have been no studies that apply this method for multi-criteria decision making in milling.

From the above arguments, this study will conduct an experiment on the milling process according to the matrix designed by the Taguchi method. The PIV method will be applied for multi-criteria decision making. The ultimate goal of this study is to determine the type of insert material, nose radius, cutting velocity, feed rate and depth of cut in order to simultaneously ensure the minimum surface roughness and the maximum $M R R$. The results of this study can be directly applied to the selection of the insert material, the nose radius, and the cutting parameters to ensure the minimum surface roughness and the maximum MRR when milling SCM440 steel. In addition, the methodology presented in this study can also be applied to perform multi-criteria decisionmaking studies in other machining processes.

\section{MILLING EXPERIMENT}

HAAS 3-axis CNC milling machine was used to perform the experiments. This machine uses HASS (USA) operating system, using touch screen. The tool travel in the $\mathrm{X}, \mathrm{Y}$ and $\mathrm{Z}$ directions is $3048 \mathrm{~mm}, 813 \mathrm{~mm}$ and $762 \mathrm{~mm}$, respectively.
The maximum speed of the spindle is $7500 \mathrm{rpm}$, the power is $22.4 \mathrm{KW}$. The maximum feed rates along the $X, Y$, and $Z$ axes are $9.1 \mathrm{~m} / \mathrm{min}, 15.2 \mathrm{~m} / \mathrm{min}$ and $15.2 \mathrm{~mm} / \mathrm{min}$, respectively. The tool holder is SMTC type, can hold thirtyone tools at the same time. Spindle speed and feed speed in all directions are steplessly adjusted according to the intended use.

SCM440 steel was selected to perform the experiments in this study. This steel has a hight content of $\mathrm{Cr}$ and $\mathrm{Mo}$. Thanks to that, it has the advantage of high hardness but still ensures toughness. This steel is often used to make parts that are subject to heavy loads and require high wear resistance such as gears, plastic injection molds, sliding surfaces or some parts in automobile engines. These parts often have planes that need to be machined to ensure high accuracy. The workpieces has the length, width, and height of $100 \mathrm{~mm}, 50$ $\mathrm{mm}$, and $40 \mathrm{~mm}$, respectively. Before performing the experiments, the workpieces were subjected to rough milling to ensure the same size and quality of all samples. The experimental matrix was designed according to the Taguchi method with five input parameters including insert material, nose radius, cutting velocity, feed rate and depth of cut. Each input parameter is selected with three value levels as shown in Table 1. The selection of values for input parameters according to their values in the study [11]. The experimental matrix of twenty-seven experiments is shown in Table 2. In each experiment, two new inserts of the same type with the diameter of $14 \mathrm{~mm}$ were installed on the tool body, these two inserts were installed symmetrically. The fact that each chip is used only once is intended to reduce the influence of flank wear on responses.

During the experiment, the coolant was Tectyl cool 240 (Korea) oil, mixed with water to reach a concentration of $8 \%$, with a flow of 22 liters $/ \mathrm{min}$. This coolant type is commonly used in CNC milling technology [16].

Surface roughness was measured with the SJ201 machine of Mitutoyo - Japan, with the standard length of the measurement being $0.8 \mathrm{~mm}$. Before surface roughness measurement, the workpieces were washed with alcohol, then allowed to dry. The purpose of this is to ensure the surface of the part is clean and pure, ensuring the accuracy of the measurement. In addition, in order to minimize the errors that may appear in the measurement process, each sample was measured at least three times in a row. Taking the average value of consecutive measurements, we will get the surface roughness value at each experiment.

$M R R$ is calculated according to formula (1).

$$
M R R=V_{f} \cdot a_{p} . b_{w}\left(\mathrm{~mm}^{3} / \mathrm{min}\right)
$$

Of which:

$V_{f}$ : is the feed rate in minutes.

$b_{w}$ is the milling width. In this case a symmetrical milling was performed, which means that the milling width is equal to the diameter of the tool itself, i.e. $b_{w}=14 \mathrm{~mm}$. 
Table 1. The value of input parameters at levels

\begin{tabular}{|c|c|c|c|c|c|}
\hline \multirow{2}{*}{ Parameter } & \multirow{2}{*}{ Symbol } & \multirow{2}{*}{ Unit } & \multicolumn{3}{|c|}{ Value at levels } \\
\cline { 3 - 6 } & & & 1 & 2 & 3 \\
\hline Insert material & $I M$ & - & TiN & TiCN & TiAlN \\
\hline Tool nose radius & $r$ & $\mathrm{~mm}$ & 0.3 & 0.5 & 0.8 \\
\hline Cutting velocity & $v_{c}$ & $\mathrm{~m} / \mathrm{min}$ & 100 & 125 & 150 \\
\hline Feed rate & $V_{f}$ & $\mathrm{~mm} / \mathrm{min}$ & 300 & 400 & 500 \\
\hline Depth of cut & $a_{p}$ & $\mathrm{~mm}$ & 0.25 & 0.35 & 0.45 \\
\hline
\end{tabular}

Table 2. Experimental matrix and results

\begin{tabular}{|c|c|c|c|c|c|c|c|c|c|c|c|c|}
\hline \multirow[b]{2}{*}{ Trial } & \multicolumn{5}{|c|}{ Code value } & \multicolumn{5}{|c|}{ Actual value } & \multicolumn{2}{|c|}{ Response } \\
\hline & $I M$ & $r$ & $v_{c}$ & $f_{z}$ & $a_{p}$ & $I M$ & $\begin{array}{c}r \\
(\mathrm{~mm})\end{array}$ & $\begin{array}{c}v_{c} \\
(\mathrm{~m} / \mathrm{min})\end{array}$ & $\begin{array}{c}V_{f} \\
(\mathrm{~mm} / \mathrm{min})\end{array}$ & $a_{p}(\mathrm{~mm})$ & $\begin{array}{c}R a \\
(\mu \mathrm{m})\end{array}$ & $\begin{array}{c}M R R \\
\left(\mathrm{~mm}^{3} / \mathrm{min}\right)\end{array}$ \\
\hline 1 & 1 & 1 & 1 & 1 & 1 & $\mathrm{TiN}$ & 0.3 & 100 & 300 & 0.25 & 0.823 & 1050 \\
\hline 2 & 1 & 1 & 1 & 1 & 2 & TiN & 0.3 & 100 & 300 & 0.35 & 1.556 & 1470 \\
\hline 3 & 1 & 1 & 1 & 1 & 3 & TiN & 0.3 & 100 & 300 & 0.45 & 1.812 & 1890 \\
\hline 4 & 1 & 2 & 2 & 2 & 1 & TiN & 0.5 & 125 & 400 & 0.25 & 1.642 & 1400 \\
\hline 5 & 1 & 2 & 2 & 2 & 2 & $\mathrm{TiN}$ & 0.5 & 125 & 400 & 0.35 & 0.966 & 1960 \\
\hline 6 & 1 & 2 & 2 & 2 & 3 & TiN & 0.5 & 125 & 400 & 0.45 & 1.053 & 2520 \\
\hline 7 & 1 & 3 & 3 & 3 & 1 & TiN & 0.8 & 150 & 500 & 0.25 & 2.355 & 1750 \\
\hline 8 & 1 & 3 & 3 & 3 & 2 & TiN & 0.8 & 150 & 500 & 0.35 & 1.690 & 2450 \\
\hline 9 & 1 & 3 & 3 & 3 & 3 & TiN & 0.8 & 150 & 500 & 0.45 & 0.921 & 3150 \\
\hline 10 & 2 & 1 & 2 & 3 & 1 & TiCN & 0.3 & 125 & 500 & 0.25 & 0.267 & 1750 \\
\hline 11 & 2 & 1 & 2 & 3 & 2 & TiCN & 0.3 & 125 & 500 & 0.35 & 0.327 & 2450 \\
\hline 12 & 2 & 1 & 2 & 3 & 3 & TiCN & 0.3 & 125 & 500 & 0.45 & 0.733 & 3150 \\
\hline 13 & 2 & 2 & 3 & 1 & 1 & TiCN & 0.5 & 150 & 300 & 0.25 & 0.985 & 1050 \\
\hline 14 & 2 & 2 & 3 & 1 & 2 & TiCN & 0.5 & 150 & 300 & 0.35 & 2.661 & 1470 \\
\hline 15 & 2 & 2 & 3 & 1 & 3 & TiCN & 0.5 & 150 & 300 & 0.45 & 0.928 & 1890 \\
\hline 16 & 2 & 3 & 1 & 2 & 1 & TiCN & 0.8 & 100 & 400 & 0.25 & 0.902 & 1400 \\
\hline 17 & 2 & 3 & 1 & 2 & 2 & TiCN & 0.8 & 100 & 400 & 0.35 & 2.829 & 1960 \\
\hline 18 & 2 & 3 & 1 & 2 & 3 & TiCN & 0.8 & 100 & 400 & 0.45 & 1.418 & 2520 \\
\hline 19 & 3 & 1 & 3 & 2 & 1 & TiAlN & 0.3 & 150 & 400 & 0.25 & 0.508 & 1400 \\
\hline 20 & 3 & 1 & 3 & 2 & 2 & TiAlN & 0.3 & 150 & 400 & 0.35 & 0.287 & 1960 \\
\hline 21 & 3 & 1 & 3 & 2 & 3 & TiAlN & 0.3 & 150 & 400 & 0.45 & 0.481 & 2520 \\
\hline 22 & 3 & 2 & 1 & 3 & 1 & TiAlN & 0.5 & 100 & 500 & 0.25 & 1.209 & 1750 \\
\hline 23 & 3 & 2 & 1 & 3 & 2 & TiAlN & 0.5 & 100 & 500 & 0.35 & 2.681 & 2450 \\
\hline 24 & 3 & 2 & 1 & 3 & 3 & TiAlN & 0.5 & 100 & 500 & 0.45 & 0.728 & 3150 \\
\hline 25 & 3 & 3 & 2 & 1 & 1 & TiAlN & 0.8 & 125 & 300 & 0.25 & 0.758 & 1050 \\
\hline 26 & 3 & 3 & 2 & 1 & 2 & TiAlN & 0.8 & 125 & 300 & 0.35 & 2.153 & 1470 \\
\hline 27 & 3 & 3 & 2 & 1 & 3 & TiAlN & 0.8 & 125 & 300 & 0.45 & 2.225 & 1890 \\
\hline
\end{tabular}

\section{EXPERIMENT RESULTS AND DISCUSSION}

The experimental results have also been included in Table 2 . Figure 1 shows a chart representing the influence of input parameters on the surface roughness. The influence of the interaction between input parameters on the surface roughness is presented in Figure 2. 


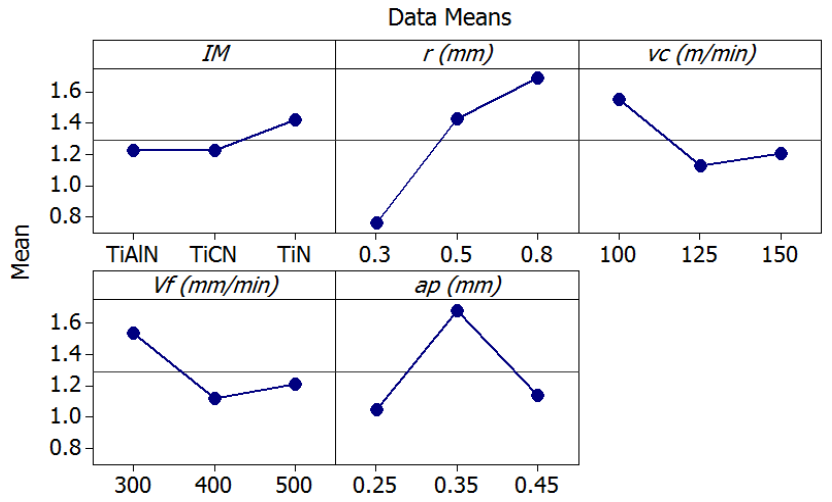

Figure 1. Main effects plot for Ra

Based on the difference between the points represented at level 1 and level 3 of each graph in Figure 1, it shows that the nose radius is the parameter with the greatest influence on the surface roughness, followed by the influence of the cutting velocity, the feed rate has the influence on the surface roughness at position 3 , while the insert material and the depth of cut have little followed on the surface roughness. These phenomena are explained as follows. When changing the nose radius, it changes both the shape and size of the scratch left by the cutting tool on the surface of the part, thereby changing the surface roughness. When the cutting speed and the feed rate change, the contact time between a point on the workpiece surface and the cutting tool will change, that is, the degree of "re-cut" of the cutting tool to the surface will change, thus affecting the surface roughness. The type of insert material and the cutting depth have little influence on the surface roughness, which is explained by the fact that all three types of inserts have high titanium content and therefore have high temperature resistance, which is the cause of reduced phenomenon plastic deformation of the surface metal layer (plastic deformation of the surface metal layer is one of the main causes affecting the surface roughness). Therefore, changes in the insert material and cutting depth have little effect on the surface roughness.

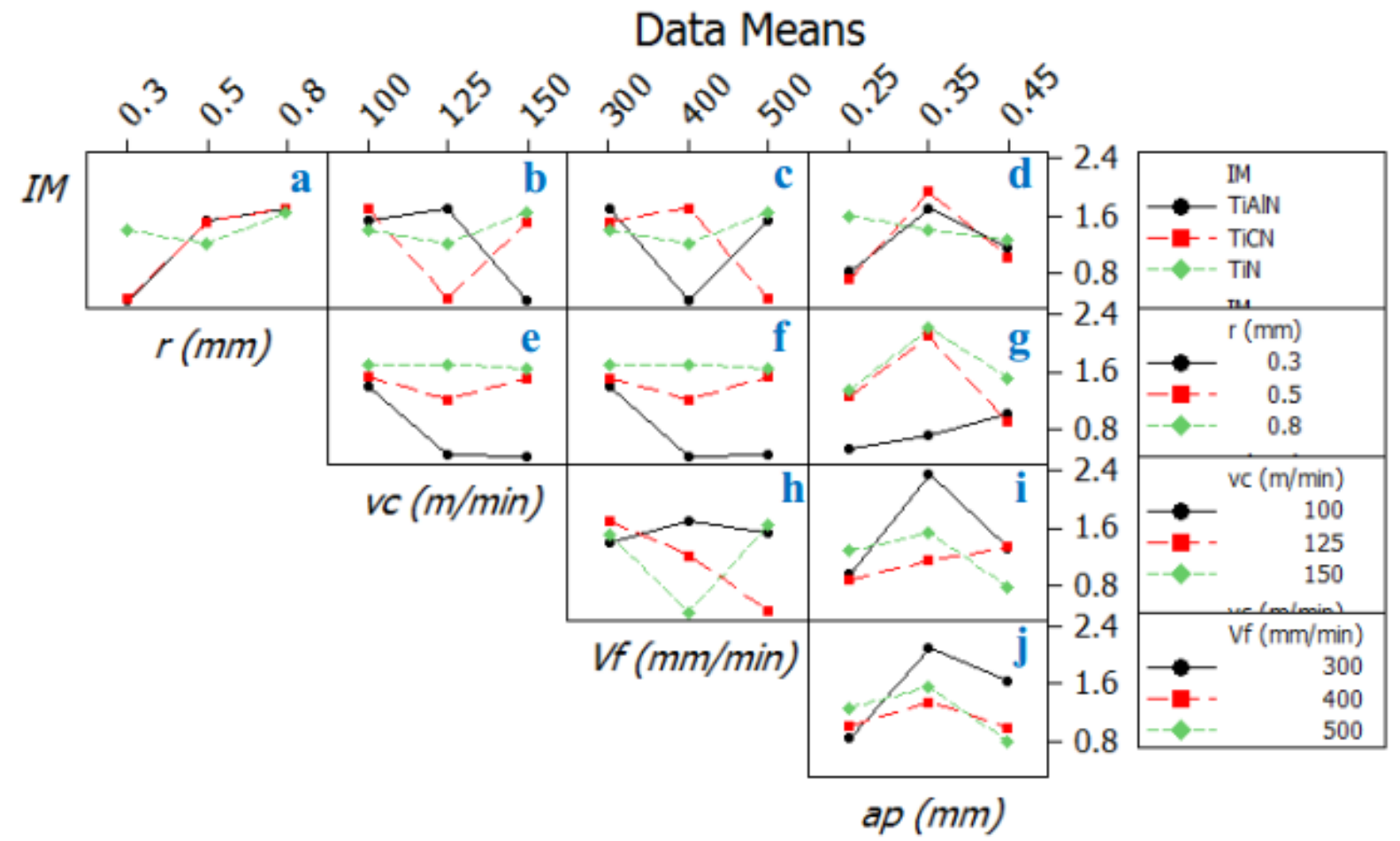

a) Interaction between $I M$ and $r$; b) Interaction between $I M$ and $v_{c}$; c) Interaction between $I M$ and $\mathrm{V}_{\mathrm{f}}$; d) Interaction between $I M$ and $a_{p} ;$ e) Interaction between $r$ and $v_{c}$; f) Interaction between $r$ and $V_{f}$, g) Interaction between $r$ and $a_{p}$; h) Interaction between $v_{c}$ and $V_{f}$; i) Interaction between $v_{c}$ and $a_{p}$; and j) Interaction between $I M$ and $a_{p}$.

Figure 2. Interaction plot for Ra

In Figure 2 there are ten sub-figures, each of which corresponds to the interaction effect between the two input parameters on the surface roughness. Observing these subfigures shows that the interaction effect of input parameters on surface roughness is very complex. Just analyzing some of these ten figures will further clarify this statement. For example, let's analyze figure $a$ and figure $b$.

- In the first sub-figure (figure a), when the insert material is TiN, the surface roughness will decrease if the nose radius increases from $0.3 \mathrm{~mm}$ to $0.5 \mathrm{~mm}$, but if the nose radius increases from $0.5 \mathrm{~mm}$ to $0.8 \mathrm{~mm}$, the surface roughness will increase. For two types of chips, TiCN and TiAlN, when the nose radius increases from $0.3 \mathrm{~mm}$ to $0.5 \mathrm{~mm}$, the surface roughness increases rapidly, but if the nose radius increases from $0.5 \mathrm{~mm}$ to $0.8 \mathrm{~mm}$, the surface roughness increases slowly.

- In the second sub-figure (figure b), when the insert material is $T i N$, the surface roughness will decrease slowly as the cutting velocity increases from $100 \mathrm{~m} / \mathrm{min}$ to $125 \mathrm{~m} / \mathrm{min}$, but if the cutting velocity increases from $125 \mathrm{~m} / \mathrm{min}$ to 150 
$\mathrm{m} / \mathrm{min}$, the surface roughness will increase slowly. When the insert material is $\mathrm{TiCN}$, the surface roughness will decrease rapidly if the cutting velocity increases from $100 \mathrm{~m} / \mathrm{min}$ to $125 \mathrm{~m} / \mathrm{min}$, but the surface roughness will increase rapidly if the cutting velocity increases from $125 \mathrm{~m} / \mathrm{min}$ to $150 \mathrm{~m} / \mathrm{min}$. In the case the insert material is TiAlN, if the cutting velocity increases from $100 \mathrm{~m} / \mathrm{min}$ to $125 \mathrm{~m} / \mathrm{min}$, the surface roughness increases slowly, but if the cutting velocity increases from $125 \mathrm{~m} / \mathrm{min}$ to $150 \mathrm{~m} / \mathrm{min}$, the surface roughness will decrease rapidly.

The detailed analysis above indicates that the input parameters and their interactions have a very complex influence on the surface roughness. When simultaneously considering two parameters, surface roughness and $M R R$, it is also shown that the input parameters have a very complex influence on both of these parameters. It can be said that because as analyzed above (for example: considering Figure $1)$, the depth of cut has little influence on the surface roughness but has much influence on $M R R$. In contrast, the cutting velocity has significant influence on the surface roughness but had no influence on MRR. Similarly, the nose radius has great influence on the surface roughness but has no influence on MRR. Thereby, it shows that it is impossible to determine the value of input parameters to simultaneously ensure the minimum surface roughness and the maximum MRR if only observing the graph in Figures 1 and 2.

When observing the experimental data in Table 2, it shows that $M R R$ has the maximum value of $3150 \mathrm{~mm}^{3} / \mathrm{min}$ in experiments 9, 12 and 24. But also in these experiments, the surface roughness has the corresponding values of $0.921 \mu \mathrm{m}$, $0.733 \mu \mathrm{m}$ and $0.728 \mu \mathrm{m}$. These three values are not the minimum one for surface roughness in Table 2. The minimum value of surface roughness is $0.267 \mu \mathrm{m}$, corresponding to experiment 10 , but $M R R$ in this experiment is quite small (equal to $1750 \mathrm{~mm}^{3} / \mathrm{min}$ ). This affirms that it is impossible to obtain an experiment at which the minimum surface roughness and the maximum $M R R$ are simultaneously guaranteed. The concept of "minimum" for surface roughness and the concept of "maximum" for $M R R$ can only be understood relatively. And of course, in order to determine the experiment at which the "minimum" surface roughness and the "maximum" MRR are simultaneously guaranteed, it is necessary to study multi-criteria decision making. This content will be presented in the next part of this article.

\section{MULTI-CRITERIA DECISION MALKING WHEN MILLING}

\section{A. PIV method}

$P I V$ is a method for multi-criteria decision making that was first introduced in 2018 [8]. The steps to implement multi- criteria decision making according to this method are as follows:

Step 1: Describe solutions $A i$ (with $j=1,2, \ldots, m$ ) and criteria $C i$ (with $j=1,2, \ldots ., n$ ).

Step 2. Build a decision-making matrix $Y$ by arranging the solutions by rows and the criteria by columns as in the form of formula (2).

$$
Y=\left[Y_{i j}\right]_{m \times n}=\left[\begin{array}{cccccc}
Y_{11} & Y_{12} & \cdots & Y_{1 j} & \cdots & Y_{1 n} \\
Y_{21} & Y_{22} & \cdots & \cdots & \cdots & Y_{2 n} \\
\cdots & \cdots & \cdots & \cdots & \cdots & \cdots \\
Y_{i 1} & \cdots & \cdots & Y_{i j} & \cdots & Y_{i n} \\
\cdots & \cdots & \cdots & \cdots & \cdots & \cdots \\
Y_{m 1} & \cdots & \cdots & Y_{m j} & \cdots & Y_{m n}
\end{array}\right]
$$

Of which $Y_{i j}$ represents the alternative performance value of the criterion $j$ in the solution $i$.

Step 3: Determine the normalized decision-making matrix using the formula (3)

$$
R_{j}=\frac{Y_{j}}{\sqrt{\sum_{i=1}^{m} Y_{j}^{2}}}
$$

Of which $Y i$ is the actual decision value of option $i$.

Step 4: Determine the weighted normalized decision-making matrix according to the formula (4)

$$
v_{j}=\mathrm{w}_{\mathrm{j}} \times R_{j}
$$

Of which $w_{j}$ is the weight of the criterion $j$.

Step 5: Evaluate the weighted proximity index according to the formula (5).

$$
u_{i}=\left\{\begin{array}{lc}
v_{\max }-v_{i} & \text { for beneficial attributes } \\
v_{i}-v_{\min } & \text { for } \cos t \text { attributes }
\end{array}\right.
$$

Step 6. Determine the overall proximity value according to the formula (6).

$$
d_{i}=\sum_{j=1}^{n} u_{i}
$$

Step 7. Rank the solutions according to the principle that the solution with the smallest $d_{i}$ is the best one.

\section{B. Multi-criteria decision making}

In order to facilitate the calculation process, we put $I M=X_{l}$, $r=X_{2}, v_{c}=X_{3}, V_{f}=X_{4}, a_{p}=X_{5}, R_{a}=Y_{1}, M R R=Y_{2}$. Thus, we have the decision-making matrix as shown in Table 3. The task of the multi-criteria decision making problem is to choose the solution $A_{i}$ where $Y_{l i}$ is considered the minimum and $Y_{2 i}$ is considered the maximum.

Table 3. Decision-making matrix

\begin{tabular}{|c|c|c|c|c|c|c|c|}
\hline Solutions & $X_{1}$ & $X_{2}$ & $X_{3}$ & $X_{4}$ & $X_{5}$ & $Y_{1}$ & $Y_{2}$ \\
\hline $\mathrm{A}_{1}$ & $\mathrm{TiN}$ & 0.3 & 100 & 300 & 0.25 & 0.823 & 1050 \\
\hline $\mathrm{A}_{2}$ & $\mathrm{TiN}$ & 0.3 & 100 & 300 & 0.35 & 1.556 & 1470 \\
\hline $\mathrm{A}_{3}$ & $\mathrm{TiN}$ & 0.3 & 100 & 300 & 0.45 & 1.812 & 1890 \\
\hline
\end{tabular}




\begin{tabular}{|l|l|l|l|l|l|l|l|}
\hline $\mathrm{A}_{4}$ & TiN & 0.5 & 125 & 400 & 0.25 & 1.642 & 1400 \\
\hline $\mathrm{A}_{5}$ & TiN & 0.5 & 125 & 400 & 0.35 & 0.966 & 1960 \\
\hline $\mathrm{A}_{6}$ & TiN & 0.5 & 125 & 400 & 0.45 & 1.053 & 2520 \\
\hline $\mathrm{A}_{7}$ & TiN & 0.8 & 150 & 500 & 0.25 & 2.355 & 1750 \\
\hline $\mathrm{A}_{8}$ & TiN & 0.8 & 150 & 500 & 0.35 & 1.690 & 2450 \\
\hline $\mathrm{A}_{9}$ & TiN & 0.8 & 150 & 500 & 0.45 & 0.921 & 3150 \\
\hline $\mathrm{A}_{10}$ & TiCN & 0.3 & 125 & 500 & 0.25 & 0.267 & 1750 \\
\hline $\mathrm{A}_{11}$ & TiCN & 0.3 & 125 & 500 & 0.35 & 0.327 & 2450 \\
\hline $\mathrm{A}_{12}$ & TiCN & 0.3 & 125 & 500 & 0.45 & 0.733 & 3150 \\
\hline $\mathrm{A}_{13}$ & TiCN & 0.5 & 150 & 300 & 0.25 & 0.985 & 1050 \\
\hline $\mathrm{A}_{14}$ & TiCN & 0.5 & 150 & 300 & 0.35 & 2.661 & 1470 \\
\hline $\mathrm{A}_{15}$ & TiCN & 0.5 & 150 & 300 & 0.45 & 0.928 & 1890 \\
\hline $\mathrm{A}_{16}$ & TiCN & 0.8 & 100 & 400 & 0.25 & 0.902 & 1400 \\
\hline $\mathrm{A}_{17}$ & TiCN & 0.8 & 100 & 400 & 0.35 & 2.829 & 1960 \\
\hline $\mathrm{A}_{18}$ & TiCN & 0.8 & 100 & 400 & 0.45 & 1.418 & 2520 \\
\hline $\mathrm{A}_{19}$ & TiAlN & 0.3 & 150 & 400 & 0.25 & 0.508 & 1400 \\
\hline $\mathrm{A}_{20}$ & TiAlN & 0.3 & 150 & 400 & 0.35 & 0.287 & 1960 \\
\hline $\mathrm{A}_{21}$ & TiAlN & 0.3 & 150 & 400 & 0.45 & 0.481 & 2520 \\
\hline $\mathrm{A}_{22}$ & TiAlN & 0.5 & 100 & 500 & 0.25 & 1.209 & 1750 \\
\hline $\mathrm{A}_{23}$ & TiAlN & 0.5 & 100 & 500 & 0.35 & 2.681 & 2450 \\
\hline $\mathrm{A}_{24}$ & TiAlN & 0.5 & 100 & 500 & 0.45 & 0.728 & 3150 \\
\hline $\mathrm{A}_{25}$ & TiAlN & 0.8 & 125 & 300 & 0.25 & 0.758 & 1050 \\
\hline $\mathrm{A}_{26}$ & TiAlN & 0.8 & 125 & 300 & 0.35 & 2.153 & 1470 \\
\hline $\mathrm{A}_{27}$ & TiAlN & 0.8 & 125 & 300 & 0.45 & 2.225 & 1890 \\
\hline
\end{tabular}

Apply the formula (3), it is able to determine the normalized matrix as shown in Table 4.

Table 4. Normalized Matrix

\begin{tabular}{|c|c|c|}
\hline \multirow{2}{*}{ Solutions } & \multicolumn{2}{|c|}{$R_{j}$} \\
\cline { 2 - 3 } & $Y_{1}$ & $Y_{2}$ \\
\hline $\mathrm{A}_{1}$ & 0.0869 & 103.2926 \\
\hline $\mathrm{A}_{2}$ & 0.3107 & 202.4534 \\
\hline $\mathrm{A}_{3}$ & 0.4213 & 334.6679 \\
\hline $\mathrm{A}_{4}$ & 0.3460 & 183.6312 \\
\hline $\mathrm{A}_{5}$ & 0.1197 & 359.9172 \\
\hline $\mathrm{A}_{6}$ & 0.1423 & 594.9652 \\
\hline $\mathrm{A}_{7}$ & 0.7116 & 286.9238 \\
\hline $\mathrm{A}_{8}$ & 0.3665 & 562.3707 \\
\hline $\mathrm{A}_{9}$ & 0.1088 & 929.6331 \\
\hline $\mathrm{A}_{10}$ & 0.0091 & 286.9238 \\
\hline $\mathrm{A}_{11}$ & 0.0137 & 562.3707 \\
\hline $\mathrm{A}_{12}$ & 0.0689 & 929.6331 \\
\hline
\end{tabular}

\begin{tabular}{|l|l|l|}
\hline $\mathrm{A}_{13}$ & 0.1245 & 103.2926 \\
\hline $\mathrm{A}_{14}$ & 0.9086 & 202.4534 \\
\hline $\mathrm{A}_{15}$ & 0.1105 & 334.6679 \\
\hline $\mathrm{A}_{16}$ & 0.1044 & 183.6312 \\
\hline $\mathrm{A}_{17}$ & 1.0269 & 359.9172 \\
\hline $\mathrm{A}_{18}$ & 0.2580 & 594.9652 \\
\hline $\mathrm{A}_{19}$ & 0.0331 & 183.6312 \\
\hline $\mathrm{A}_{20}$ & 0.0106 & 359.9172 \\
\hline $\mathrm{A}_{21}$ & 0.0297 & 594.9652 \\
\hline $\mathrm{A}_{22}$ & 0.1876 & 286.9238 \\
\hline $\mathrm{A}_{23}$ & 0.9223 & 562.3707 \\
\hline $\mathrm{A}_{24}$ & 0.0680 & 929.6331 \\
\hline $\mathrm{A}_{25}$ & 0.0737 & 103.2926 \\
\hline $\mathrm{A}_{26}$ & 0.5948 & 202.4534 \\
\hline $\mathrm{A}_{27}$ & 0.6352 & 334.6679 \\
\hline
\end{tabular}

Apply the formula (4) to determine the weighted normalized matrix as shown in Table 5. Of which the determination of 
the weight to the surface roughness and $M R R$ is done according to the opinion of experts. These viewpoints suggest that the weight of these two parameters should be equal, i.e. $w_{1}=w_{2}=0.5$.

Table 5. Weighted Normalized Matrix

\begin{tabular}{|c|c|c|}
\hline \multirow{2}{*}{ Solutions } & \multicolumn{2}{|c|}{$V_{i}$} \\
\cline { 2 - 3 } & $Y_{1}$ & $Y_{2}$ \\
\hline $\mathrm{A}_{1}$ & 0.0435 & 51.6463 \\
\hline $\mathrm{A}_{2}$ & 0.1553 & 101.2267 \\
\hline $\mathrm{A}_{3}$ & 0.2106 & 167.3340 \\
\hline $\mathrm{A}_{4}$ & 0.1730 & 91.8156 \\
\hline $\mathrm{A}_{5}$ & 0.0599 & 179.9586 \\
\hline $\mathrm{A}_{6}$ & 0.0711 & 297.4826 \\
\hline $\mathrm{A}_{7}$ & 0.3558 & 143.4619 \\
\hline $\mathrm{A}_{8}$ & 0.1832 & 281.1853 \\
\hline $\mathrm{A}_{9}$ & 0.0544 & 464.8166 \\
\hline $\mathrm{A}_{10}$ & 0.0046 & 143.4619 \\
\hline $\mathrm{A}_{11}$ & 0.0069 & 281.1853 \\
\hline $\mathrm{A}_{12}$ & 0.0345 & 464.8166 \\
\hline $\mathrm{A}_{13}$ & 0.0622 & 51.6463 \\
\hline $\mathrm{A}_{14}$ & 0.4543 & 101.2267 \\
\hline $\mathrm{A}_{15}$ & 0.0553 & 167.3340 \\
\hline $\mathrm{A}_{16}$ & 0.0522 & 91.8156 \\
\hline $\mathrm{A}_{17}$ & 0.5135 & 179.9586 \\
\hline $\mathrm{A}_{18}$ & 0.1290 & 297.4826 \\
\hline $\mathrm{A}_{19}$ & 0.0166 & 91.8156 \\
\hline $\mathrm{A}_{20}$ & 0.0053 & 179.9586 \\
\hline $\mathrm{A}_{21}$ & 0.0148 & 297.4826 \\
\hline $\mathrm{A}_{22}$ & 0.0938 & 143.4619 \\
\hline $\mathrm{A}_{23}$ & 0.4611 & 281.1853 \\
\hline $\mathrm{A}_{24}$ & 0.0340 & 464.8166 \\
\hline $\mathrm{A}_{25}$ & 0.0369 & 51.6463 \\
\hline $\mathrm{A}_{26}$ & 0.2974 & 101.2267 \\
\hline $\mathrm{A}_{27}$ & 0.3176 & 167.3340 \\
\hline & & \\
\hline & & \\
\hline
\end{tabular}

Apply the formula (5) to determine the proximity index as shown in Table 6. Apply the formula (6) to determine the total proximity value, also included in Table 6 .
Table 6. Several parameters in $P I V$

\begin{tabular}{|c|c|c|c|}
\hline \multirow{2}{*}{ Solutions } & \multicolumn{2}{|c|}{$u_{i}$} & \multirow{2}{*}{$d_{i}$} \\
\cline { 2 - 3 } & $Y_{1}$ & $Y_{2}$ & \\
\hline $\mathrm{A}_{1}$ & 0.039 & 413.170 & 413.2092 \\
\hline $\mathrm{A}_{2}$ & 0.151 & 363.590 & 363.7406 \\
\hline $\mathrm{A}_{3}$ & 0.206 & 297.483 & 297.6887 \\
\hline $\mathrm{A}_{4}$ & 0.168 & 373.001 & 373.1693 \\
\hline $\mathrm{A}_{5}$ & 0.055 & 284.858 & 284.9132 \\
\hline $\mathrm{A}_{6}$ & 0.067 & 167.334 & 167.4005 \\
\hline $\mathrm{A}_{7}$ & 0.351 & 321.355 & 321.7059 \\
\hline $\mathrm{A}_{8}$ & 0.179 & 183.631 & 183.8099 \\
\hline $\mathrm{A}_{9}$ & 0.050 & 0.000 & 0.0498 \\
\hline $\mathrm{A}_{10}$ & 0.000 & 321.355 & 321.3547 \\
\hline $\mathrm{A}_{11}$ & 0.002 & 183.631 & 183.6335 \\
\hline $\mathrm{A}_{12}$ & 0.030 & 0.000 & 0.0299 \\
\hline $\mathrm{A}_{13}$ & 0.058 & 413.170 & 413.2279 \\
\hline $\mathrm{A}_{14}$ & 0.450 & 363.590 & 364.0396 \\
\hline $\mathrm{A}_{15}$ & 0.051 & 297.483 & 297.5333 \\
\hline $\mathrm{A}_{16}$ & 0.048 & 373.001 & 373.0486 \\
\hline $\mathrm{A}_{17}$ & 0.509 & 284.858 & 285.3668 \\
\hline $\mathrm{A}_{18}$ & 0.124 & 167.334 & 167.4584 \\
\hline $\mathrm{A}_{19}$ & 0.012 & 373.001 & 373.0129 \\
\hline $\mathrm{A}_{20}$ & 0.001 & 284.858 & 284.8587 \\
\hline $\mathrm{A}_{21}$ & 0.010 & 167.334 & 167.3442 \\
\hline $\mathrm{A}_{22}$ & 0.089 & 321.355 & 321.4439 \\
\hline $\mathrm{A}_{23}$ & 0.457 & 183.631 & 184.0878 \\
\hline $\mathrm{A}_{24}$ & 0.029 & 0.000 & 0.0294 \\
\hline $\mathrm{A}_{25}$ & 0.032 & 413.170 & 413.2026 \\
\hline $\mathrm{A}_{26}$ & 0.293 & 363.590 & 363.8827 \\
\hline $\mathrm{A}_{27}$ & 0.313 & 297.483 & 297.7956 \\
\hline & & & \\
\hline
\end{tabular}

The solutions are ranked based on the values of $d_{i}$, the results are presented in Table 7.

Table 7. Ranking of solutions by the value of $d_{i}$

\begin{tabular}{|c|c|c|c|c|c|c|c|c|}
\hline Solutions & $I M$ & $r(\mathrm{~mm})$ & $v_{c}(\mathrm{~m} / \mathrm{min})$ & $\begin{array}{c}f_{z} \\
(\mathrm{~mm} / \mathrm{min})\end{array}$ & $a_{p}(\mathrm{~mm})$ & $\begin{array}{c}R a \\
(\mu \mathrm{m})\end{array}$ & $\begin{array}{c}M R R \\
\left(\mathrm{~mm}^{3} / \mathrm{min}^{2}\right.\end{array}$ & Rank \\
\hline $\mathrm{A}_{1}$ & TiN & 0.3 & 100 & 300 & 0.25 & 0.823 & 1050 & 26 \\
\hline $\mathrm{A}_{2}$ & TiN & 0.3 & 100 & 300 & 0.35 & 1.556 & 1470 & 19 \\
\hline $\mathrm{A}_{3}$ & TiN & 0.3 & 100 & 300 & 0.45 & 1.812 & 1890 & 14 \\
\hline
\end{tabular}




\begin{tabular}{|c|c|c|c|c|c|c|c|c|}
\hline $\mathrm{A}_{4}$ & TiN & 0.5 & 125 & 400 & 0.25 & 1.642 & 1400 & 23 \\
\hline $\mathrm{A}_{5}$ & TiN & 0.5 & 125 & 400 & 0.35 & 0.966 & 1960 & 11 \\
\hline $\mathrm{A}_{6}$ & TiN & 0.5 & 125 & 400 & 0.45 & 1.053 & 2520 & 5 \\
\hline $\mathrm{A}_{7}$ & TiN & 0.8 & 150 & 500 & 0.25 & 2.355 & 1750 & 18 \\
\hline $\mathrm{A}_{8}$ & TiN & 0.8 & 150 & 500 & 0.35 & 1.690 & 2450 & 8 \\
\hline $\mathrm{A}_{9}$ & TiN & 0.8 & 150 & 500 & 0.45 & 0.921 & 3150 & 3 \\
\hline $\mathrm{A}_{10}$ & TiCN & 0.3 & 125 & 500 & 0.25 & 0.267 & 1750 & 16 \\
\hline $\mathrm{A}_{11}$ & TiCN & 0.3 & 125 & 500 & 0.35 & 0.327 & 2450 & 7 \\
\hline $\mathrm{A}_{12}$ & TiCN & 0.3 & 125 & 500 & 0.45 & 0.733 & 3150 & 2 \\
\hline $\mathrm{A}_{13}$ & TiCN & 0.5 & 150 & 300 & 0.25 & 0.985 & 1050 & 27 \\
\hline $\mathrm{A}_{14}$ & TiCN & 0.5 & 150 & 300 & 0.35 & 2.661 & 1470 & 20 \\
\hline $\mathrm{A}_{15}$ & TiCN & 0.5 & 150 & 300 & 0.45 & 0.928 & 1890 & 13 \\
\hline $\mathrm{A}_{16}$ & TiCN & 0.8 & 100 & 400 & 0.25 & 0.902 & 1400 & 22 \\
\hline $\mathrm{A}_{17}$ & TiCN & 0.8 & 100 & 400 & 0.35 & 2.829 & 1960 & 12 \\
\hline $\mathrm{A}_{18}$ & TiCN & 0.8 & 100 & 400 & 0.45 & 1.418 & 2520 & 6 \\
\hline $\mathrm{A}_{19}$ & TiAlN & 0.3 & 150 & 400 & 0.25 & 0.508 & 1400 & 21 \\
\hline $\mathrm{A}_{20}$ & TiAlN & 0.3 & 150 & 400 & 0.35 & 0.287 & 1960 & 10 \\
\hline $\mathrm{A}_{21}$ & TiAlN & 0.3 & 150 & 400 & 0.45 & 0.481 & 2520 & 4 \\
\hline $\mathrm{A}_{22}$ & TiAlN & 0.5 & 100 & 500 & 0.25 & 1.209 & 1750 & 17 \\
\hline $\mathrm{A}_{23}$ & TiAlN & 0.5 & 100 & 500 & 0.35 & 2.681 & 2450 & 9 \\
\hline $\mathrm{A}_{24}$ & TiAlN & 0.5 & 100 & 500 & 0.45 & 0.728 & 3150 & 1 \\
\hline $\mathrm{A}_{25}$ & TiAlN & 0.8 & 125 & 300 & 0.25 & 0.758 & 1050 & 25 \\
\hline $\mathrm{A}_{26}$ & TiAlN & 0.8 & 125 & 300 & 0.35 & 2.153 & 1470 & 20 \\
\hline $\mathrm{A}_{27}$ & TiAlN & 0.8 & 125 & 300 & 0.45 & 2.225 & 1890 & 15 \\
\hline
\end{tabular}

From the ranking order of options in Table 7, it shows that the $A_{24}$ option is the best, and the $A_{13}$ option is the worst. For the option $\mathrm{A}_{13}$ (and the options $\mathrm{A}_{1}, \mathrm{~A}_{25}$ ), the $M R R$ is equal to $1050 \mathrm{~mm}^{3} / \mathrm{min}$ which is the minimum value in Table 7, and the surface roughness in the option $A_{13}$ is also quite large. For the option $\mathrm{A}_{24}$ (and the options $\mathrm{A}_{9}, \mathrm{~A}_{12}$ ), the $M R R$ is equal to $3150 \mathrm{~mm}^{3} / \mathrm{min}$ which is the maximum value in table 7 . The surface roughness in the options $\mathrm{A}_{24}$ of $0.728 \mu \mathrm{m}$ is a rather small value, only larger than the surface roughness in the options $\mathrm{A}_{10}, \mathrm{~A}_{11}, \mathrm{~A}_{19}, \mathrm{~A}_{20}$ and $\mathrm{A}_{21}$. Thus, the option $A_{24}$ has surface roughness at position 6 and $M R R$ at position 1 . Therefore, it can be said that it is completely appropriate to confirm that this option is the best. Thereby, we can come to the conclusion, in order to ensure the minimum surface roughness and the maximum $M R R$ at the same time, it is required to choose the insert material as TiAlN, the nose radius equal to $0.5 \mathrm{~mm}$, the cutting velocity equal to 100 $\mathrm{m} / \mathrm{min}$, the feed rate equal to $500 \mathrm{~mm} / \mathrm{min}$ and the depth of cut equal to $0.45 \mathrm{~mm}$.

\section{CONCLUSION}

In this study, the SCM440 steel milling experiment was conducted according to a matrix designed by the Taguchi method. At each experiment, five parameters were changed, including the insert material, nose radius, cutting velocity, feed rate and depth of cut. Surface roughness and $M R R$ are two parameters that were determined in each experiment. The PIV method was applied for multi-criteria decision making. Some conclusions are drawn as follows:

- Nose radius is the parameter that has the greatest influence on surface roughness, followed by the influence of cutting velocity and feed rate. The insert material and depth of cut have no significant influence on the surface roughness.

- In order to ensure the minimum surface roughness and maximum $M R R$ simultaneously, it is required to select the insert material as TiAlN, the value of the tip radius, cutting velocity, feed rate and depth of cut are $0.5 \mathrm{~mm}, 100 \mathrm{~m} / \mathrm{min}$, $500 \mathrm{~mm} / \mathrm{min}$ and $0.45 \mathrm{~mm}$, respectively.

- The PIV method has been successfully applied in multicriteria decision making in several studies [7, 11-14]. This method was applied for the first time and also succeeded in multi-criteria decision-making of the SCM440 steel milling process in this study. The application of PIV method for multi-criteria decision making is also a research direction that should be carried out for other machining processes.

- This study only considers two criteria to evaluate the milling process: surface roughness and MRR. In order to evaluate the milling process more comprehensively, other parameters should also be considered such as cutting force, tool wear, etc. On the other hand, the weight of the criteria 
(surface roughness and $M R R$ ) was chosen by the decision maker. The weighting of the criteria according to mathematical methods such as Entropy, Analytic Hierarchy Process $(A H P)$, etc. also need to be considered. In the future, these works will be carried out by the authors of this paper.

\section{ACKNOWLEDGMENT}

This research is funded by University of Transport and Communications (UTC) under grant number T2021-CK003.

\section{REFERENCES}

[1]. D. D. Trung, Influence of Cutting Parameters on Surface Roughness during Milling AISI 1045 Steel, Tribology in Industry, Vol. 42, No. 4, pp. 658-665, 2020, https://doi.org/10.24874/ti.969.09.20.11

[2]. K. Dudzik, The possibility of applying acoustic emission method to optimize determination of milling parameters, WSEAS transactions on Systems and Control, Vol. 15, pp. 302-310, 2020, https://doi.org/10.37394/23203.2020.15.31

[3]. C. -L. Hwang, Y. -J. Lai, Ting_Yun Liu, A new approach for multiple objective decision making. Computers \& Operations Research, Vol. 20, No. 8, pp. 889-899, 1993, https://doi.org/10.1016/0305-0548(93)90109-V

[4]. S. Opricovic, G. -H. Tzeng, Compromise solution by MCDM methods: A comparative analysis of VIKOR and TOPSIS, European Journal of Operational Research, Vol. 156, No. 2, pp. 445-455, 2004, https://doi.org/10.1016/S0377-2217(03)00020-1

[5]. W. Brauers, Optimization methods for a stakeholder society. A revolution in economic thinking by multiobjective optimization, Publisher: springer before Kluwer, https://doi.org/10.1007/978-1-4419-9178-2

[6]. Triantaphyllou, Evangelos, Multi-criteria Decision Making Methods: A Comparative Study, Springer - Science + Busines media, 2020, https://www.springer.com/gp/book/9780792366072

[7]. E. Cables Perez, M.T. Lamata, J.L. Verdegay, RIMReference Ideal Method in Multicriteria Decision Making, Information Sciences, vol. 337-338, No. 10, pp. 1-10, 2016, https://doi.org/10.1016/j.ins.2015.12.011

[8]. S. Mufazzal, S. M. Muzakkir, A New Multi-Criterion Decision Making (MCDM) Method Based on Proximity Indexed Value for Minimizing Rank Reversals, Computers \& Industrial Engineering, pp.1-38, 2018, https://doi.org/10.1016/j.cie.2018.03.045

[9]. V. Gadakh, Application of MOORA method for parametric optimization of milling process, Internationl journal of applied engineering research, Dindigul, Vol. 1, No. 4, pp. 743-758, 2011.

[10]. S. K. Shihab, A. K. Chanda, Multi Response Optimization Of Milling Process Parameters Using Moora Method, International Journal of Mechanical And Production Engineering, Vol. 3, No. 4, pp. 67-71, 2015.
[11]. D. D. Trung, Multi-objective optimization of SKD11 steel milling process by Reference Ideal Method, International journal of geology, Vol. 15, pp. 1-16, 2021, https://doi.org/10.46300/9105.2021.15.1

[12]. N. Z. Khan, T. S. A.Ansari, A. N. Siddiquee, Z. A. Khan, Selection of E-learning websites using a novel Proximity Indexed Value (PIV) MCDM method, Journal of Computers in Education, Vol. 6, pp. 241-256, 2019, https://doi.org/10.1007/s40692-019-00135-7

[13]. S. Wakeel, S. Bingol, M. N. Bashir, S. Ahmad, Selection of sustainable material for the manufacturing of complex automotive products using a new hybrid Goal Programming Model for Best Worst Method-Proximity Indexed Value method, Proceedings of the Institution of Mechanical Engineers, Part L: Journal of Materials: Design and Applications, Vol. 0, No. 0, pp. 1-15, 2020, https://doi.org/10.1177/1464420720966347

[14]. A. Ulutaş, Ç. Karakoy, An analysis of the logistics performance index of EU countries with an integrated MCDM model, Economics and Business Review, Vol. 5 (19), No. 4, pp, 49-69, 2019, https://doi.org/10.18559/ebr.2019.4.3

[15]. J. Raigar, V. S. Sharma, S. Srivastava, R. Chand, J.Singh, A decision support system for the selection of an additive manufacturing process using a new hybrid MCDM technique, Sādhanā, Vol. 45, No. 101, pp. 1-14, 2020, https://doi.org/10.1007/s12046-020-01338-w

[16]. http://daunhonchinhhang.vn/product/dau-cat-got-phanuoc-tectyl-cool-240/ (at July 20. 2021) 